\title{
Patient predictors of health-seeking behaviour for persons coughing for more than two weeks in high-burden tuberculosis communities: the case of the Western Cape, South Africa
}

\author{
Carmen Christian ${ }^{1,2^{*}}$, Cobus Burger ${ }^{1}$, Mareli Claassens ${ }^{3}$, Virginia Bond ${ }^{4,5}$ and Ronelle Burger ${ }^{1}$
}

\begin{abstract}
Background: This study aimed to analyse the patient predictors of health-seeking behaviour for persons coughing for more than 2 weeks to better understand this vulnerable and important population.

Methods: The study analysed data from a cohort study (SOCS - Secondary Outcome Cohort Study) embedded in a community randomised trial ZAMSTAR (Zambia and South Africa TB and AIDS Reduction Study) in eight high-burden TB communities in the Western Cape, South Africa. These datasets are unique as they contain TB-related data as well as data on health, health-seeking behaviour, lifestyle choices, employment, socio-economic status, education and stigma. We use uni- and multivariate logistic regressions to estimate the odds ratios of consulting for a cough (of more than 2 weeks duration) for a range of relevant patient predictors.

Results: Three hundred and forty persons consulted someone about their cough and this represents 37\% of the 922 participants who reported coughing for more than 2 weeks. In the multivariate analysis, respondents of black ethnic origin (OR 1.99, 95\% Cl 1.28-3.12, $P<0.01$ ), those with higher levels of education (OR 1.05 per year of education, 95\% Cl 1.00-1.10, $P=0.05$ ), and older respondents (OR 1.02 per year, 95\% Cl 1.01-1.04, $P<0.01$ ) had a higher likelihood of consulting for their chronic cough. Individuals who smoked (OR 0.63, 95\% Cl $0.45-0.88, P<0.01$ ) and those with higher levels of socio-economic status (OR $0.81,95 \% \mathrm{Cl} 0.71-0.92, P<0.01$ ) were less likely to consult. We find no evidence of stigma playing a role in health-seeking decisions, but caution that this may be due to the difficulty of accurately and reliably capturing stigma due to, amongst other factors, social desirability bias.

Conclusions: The low levels of consultation for a cough of more than 2 weeks suggest that there are opportunities to improve case-finding. These findings on health-seeking behaviour can assist policymakers in designing TB screening and active case-finding interventions that are targeted to the characteristics of those with a chronic cough who do not seek care.
\end{abstract}

Keywords: Presumptive TB, Chronic cough, Delayed health seeking behaviour, Consulting

* Correspondence: 18797067@sun.ac.za; cchristian@uwc.ac.za

'Department of Economics, Stellenbosch University, Matieland 7602, South

Africa

${ }^{2}$ Department of Economics, University of the Western Cape, Bellville 7535,

South Africa

Full list of author information is available at the end of the article

(c) The Author(s). 2019 Open Access This article is distributed under the terms of the Creative Commons Attribution 4.0 International License (http://creativecommons.org/licenses/by/4.0/), which permits unrestricted use, distribution, and reproduction in any medium, provided you give appropriate credit to the original author(s) and the source, provide a link to the Creative Commons license, and indicate if changes were made. The Creative Commons Public Domain Dedication waiver (http://creativecommons.org/publicdomain/zero/1.0/) applies to the data made available in this article, unless otherwise stated. 


\section{Background}

TB transmission is amplified in the context of the prevailing HIV pandemic in the WHO (World Health Organization) African region, where $31 \%$ of all new TB cases in adults are attributable to HIV infection [1]. In this context where transmissions occur more readily, delays to seeking healthcare have a higher mortality and morbidity cost [2, 3]. This translates into high health and socio-economic costs (due to loss of or decreased employment), which inevitably places a higher burden on scarce public resources $[4,5]$.

Delays in seeking healthcare for a cough may arise from the patient or the healthcare system, or, most likely, both. The focus of this study is on understanding how individual characteristics are correlated with the health-seeking decisions of symptomatic cases.

Very few studies comprehensively investigate healthseeking behaviours from the patient perspective exclusively $[6,7]$. More often, studies focus on delays in diagnosis to explore both demand and supply dynamics. However, often such approaches do not allow for a detailed exploration of patient considerations.

The most recent systematic review of delays in TB diagnosis found that evidence describing the potential risk factors for delay are heterogeneous [8]. A risk factor in one setting may cause an increased delay while in another setting, a decreased delay. For example, a Zambian study found that HIV has a positive association with the risk of diagnostic delay [9], while studies in Ghana, Spain and Thailand showed a negative association for the same risk factor [10-12]. In addition, some predictors were identified extensively in many studies (namely older age, poverty, low levels of education and lack of TB awareness) while others may only appear in one study (for example, stigma). Based on the systematic review, the following prominent patient correlates were identified, amongst others: health status, socio-economic status, stigma, age, gender, education, TB knowledge levels, smoking and drinking.

Responding to the global call to address stigma in the fight against TB [13, 14], this study is (as far as we know) the first to include a quantitative measure of $\mathrm{TB}$ stigma in modelling health-seeking behaviour. Our uniquely comprehensive data set allows us to address this gap in patient-focused analysis of health-seeking decisions. Such findings information can assist policymakers in designing more targeted TB screening and active case-finding interventions.

\section{Method}

\section{Study design and setting}

This cross-sectional study uses SOCS and other ZAMSTAR data to estimate the odds ratios of consulting for a cough (of more than 2 weeks) for relevant patient predictors.

ZAMSTAR was a community-randomised trial that aimed to reduce TB and AIDS in South Africa and Zambia, two countries with amongst the highest TB incidence rates globally (in $2010 \mathrm{~TB}$ incidence in Zambia was 495/100000 people and 948/100000 for South Africa [15]), using multiple interventions [16]. Study outcomes were measured in 2010 using prevalence surveys in communities that had TB notification rates of more than 400/100000. In addition to objective health outcomes, the prevalence surveys collected individual-level data on health-seeking behaviour (Question Q41_CAC in ZAMSTAR prevalence survey reads: 'Did you consult anybody for this cough?), socio-economic status, demographics, self-reported health status and lifestyle choices. This secondary analysis study used data from the eight ZAMSTAR communities in the Western Cape, South Africa. Respondents were aged 18 years and older.

The aim of the SOCS was to recruit TB-affected households in each of the ZAMSTAR communities in order to collect stigma-related data from confirmed TB patients and their family members [17]. This study used the TB-stigma data derived from the first and second round of the SOCS (2008 to 2009) since it was the closest in time to the ZAMSTAR prevalence survey data (2010) and therefore captured the most recent degree of TB-stigma.

These datasets - ZAMSTAR and SOCS - are unique given that they contain TB-related data as well as data on health, health-seeking behaviour, lifestyle choices, employment, socio-economic status, education and stigma. There is currently no other TB-related dataset of this size $(n=30,017)$ in South Africa that provides such a comprehensive range of variables at an individual, household and community level.

\section{Sample of interest}

The sample of interest was restricted to individuals who reported coughing for more than 2 weeks. According to TB-screening guidelines all persons who report coughing for more than 2 weeks should be screened for TB [18].

\section{Variables of interest}

The outcome variable used to capture health-seeking behaviour was a consulting dichotomised variable.

Age, education and an asset index (SES proxy) were included as continuous covariates.

The asset index was derived from household asset ownership indicators using multiple correspondence analysis (MCA) (see Multiple Correspondence Analysis and Related Methods [19] for a detailed discussion of the methodology of MCA) to derive the weights. This multidimensional approach to measuring SES is based 
on seminal work in the development economics literature [20] and is increasingly used in welfare analysis and poverty targeting studies [21]. The initial validation study of the asset index (using data from developing countries Indonesia, Nepal and Pakistan) [20] produced internally coherent results which showed distinct separations across different SES households (poor, middle and rich) for each asset. The index was also robust to the assets included and was comparable with output and poverty levels across countries.

The asset index was composed of the following SES domains: semi-durable assets (television, refrigeration, motor vehicle, mobile phone), access to electricity, dwelling type (including formal and informal structures), domestic assistance, main type of toilet (including flush toilet and bucket system), main source of drinking water (including piped sources and wells), fuel access for keeping warm (including electricity and wood) and reliance on food relief (Additional file 1).

When regressing the components of the asset index on the asset index, the signs and size of the coefficients were as expected given that ownership of or access to more (or superior) assets indicate a higher SES (Additional file 2).

The model also contained dummy variables for gender, employment status, and ethnicity (only two ethnicities were observed in the sample of interest: Individuals of Cape coloured ethnic origin and individuals of black ethnic origin). A proxy for HIV was included as a dichotomous health-status covariate.

Lifestyle-choice binary variables related to smoking and drinking (alcohol) were included. These covariates were the only lifestyle-choice variables available in the ZAMSTAR dataset.

Respondents of the SOCS survey were presented with questions or statements linked to seven TB-stigma domains: unnecessary fears of transmission, blame, experience of social exclusion, experience of being made fun of, experience of health-setting stigma, internal stigma and disclosure (Additional file 3). The first two TB-stigma domains pertain to household members of the confirmed TB patient; the remaining five pertain to the confirmed $\mathrm{TB}$ patient.

Only six of the seven stigma domains were used to create the stigma index: We regarded the disclosure of one's TB status as an outcome rather than a feature of stigma. This presented an endogeneity challenge and therefore we omitted the disclosure domain from our stigma index.

After summing the selected six stigma dummies, the composite variable was transformed into an index using the weighted arithmetic mean. For ease of interpretation, this stigma index was standardised using the z-score.

We calculated a mean stigma index per community, gender and age (Additional file 4) (in the SOCS dataset).
These mean values were used to create a stigma index for each ZAMSTAR respondent weighted according to their gender, age and the community in which they lived.

\section{Data analysis and processing}

Descriptive statistics of the covariates were conducted for the sample of interest, as well as the subgroup that consulted and the subgroup that did not. A two-sample $t$ test with equal variances (for continuous covariates) and a chi-square test (for dichotomous covariates) were used to test for significant differences between the two sub-groups.

A logistic regression was used for uni- and multivariate analyses. In the model, the dependent variable captures health-seeking behaviour and relevant independent variables include socio-economic status, demographic, health status, lifestyle choice and stigma.

In line with best practice [22], a regression-error specification test (RESET) was conducted. The model passed the test and is well-specified since the RESET result was insignificant (chi-squared $=1.82 ; P=0.18$ ).

Empirical analyses were performed using STATA (version 14.02, StataCorp LLC, College Station, TX, USA).

\section{Results}

\section{Summary of health-seeking outcomes}

Three per cent of the full ZAMSTAR sample (922 out of 30,017 persons) reported coughing for more than 2 weeks. These 922 observations constitute the sample of interest. Thirty-seven per cent (340 persons) of this sample consulted someone about their cough, while the majority - 63\% (582 persons) - did not.

\section{Socio-demographic characteristics of persons coughing for more than 2 weeks}

The summary statistics of the sample characteristics are described below (Table 1).

The mean age of those who consulted for their 2-week cough was slightly higher; 42 years compared to those who did not consult (39 years). The mean highest level of education for those who consulted and those who did not was the same - namely Grade 8 (8 years of education).

The asset index ranged from -3.08 to 1.20 with a larger index representing a higher level of SES. The negative relationship between the probability of consulting and the asset index (Fig. 1) means that individuals with higher levels of SES were less likely to consult.

Men were significantly less likely to consult than women, with $39 \%$ of those consulting being men. The employed were less likely to consult than the unemployed, while individuals of black ethnic origin were significantly more likely to consult than individuals of Cape coloured ethnic origin. 
Table 1 Summary statistics of sample characteristics, 2010

\begin{tabular}{|c|c|c|c|c|c|c|}
\hline Continuous covariates & Sample mean $(n=922)^{a}$ & Std. Dev. & 'Consult' mean $(n=340)$ & Std. Dev. & 'Did not consult' mean $(n=582)^{b}$ & Std. Dev. \\
\hline Stigma Index & -0.06 & 0.88 & -0.12 & 0.90 & -0.03 & 0.87 \\
\hline Age & 40.25 & 14.82 & 42.29 & 14.84 & 39.05 & 14.68 \\
\hline Education $^{c}$ & 7.64 & 3.63 & 7.66 & 3.68 & 7.63 & 3.60 \\
\hline Asset Index & -0.08 & 1.07 & -0.19 & 1.15 & -0.02 & 1.02 \\
\hline $\begin{array}{l}\text { Dichotomous } \\
\text { covariates }\end{array}$ & $\begin{array}{l}\text { Sample proportions } \\
(n=922)\end{array}$ & Std. Dev. & $\begin{array}{l}\text { 'Consult' proportions } \\
(n=340)\end{array}$ & Std. Dev. & $\begin{array}{l}\text { 'Did not consult' proportions } \\
(n=582)\end{array}$ & Std. Dev. \\
\hline $\operatorname{Men}^{* *}$ & 0.42 & 0.50 & 0.39 & 0.49 & 0.45 & 0.50 \\
\hline Black ethnicity ${ }^{* * *}$ & 0.84 & 0.37 & 0.91 & 0.29 & 0.80 & 0.40 \\
\hline Employed & 0.29 & 0.45 & 0.26 & 0.44 & 0.30 & 0.46 \\
\hline HIV positive & 0.19 & 0.39 & 0.22 & 0.42 & 0.17 & 0.38 \\
\hline Drinks daily & 0.06 & 0.24 & 0.07 & 0.25 & 0.06 & 0.24 \\
\hline Smoked ${ }^{* * *}$ & 0.46 & 0.50 & 0.36 & 0.48 & 0.52 & 0.50 \\
\hline
\end{tabular}

\section{Clinical and lifestyle characteristics of persons coughing for more than 2 weeks}

Twenty-two per cent of those who consulted were HIV positive, while $17 \%$ of those who did not consult were HIV positive $(P=0.063)$.

Daily drinking ranged between six and $7 \%$, with no significant differences between those who consulted and those who did not consult. The proportion of respondents who had ever smoked was significantly higher amongst those who did not consult (52\%) than amongst those who did consult (36\%).

\section{Stigma characteristics of persons coughing for more than} 2 weeks

The stigma index ranged from - 1.73 (minimum) to 1.78 (maximum) with a larger index representing a higher level of stigma. For those who consulted, the mean stigma level was significantly lower $(-0.12)$ compared to those who did not $(-0.03)$.

\section{Predictors of health-seeking behaviour}

Results for the univariate and multivariate logistic regressions (Table 2) are reported in brackets as follows:

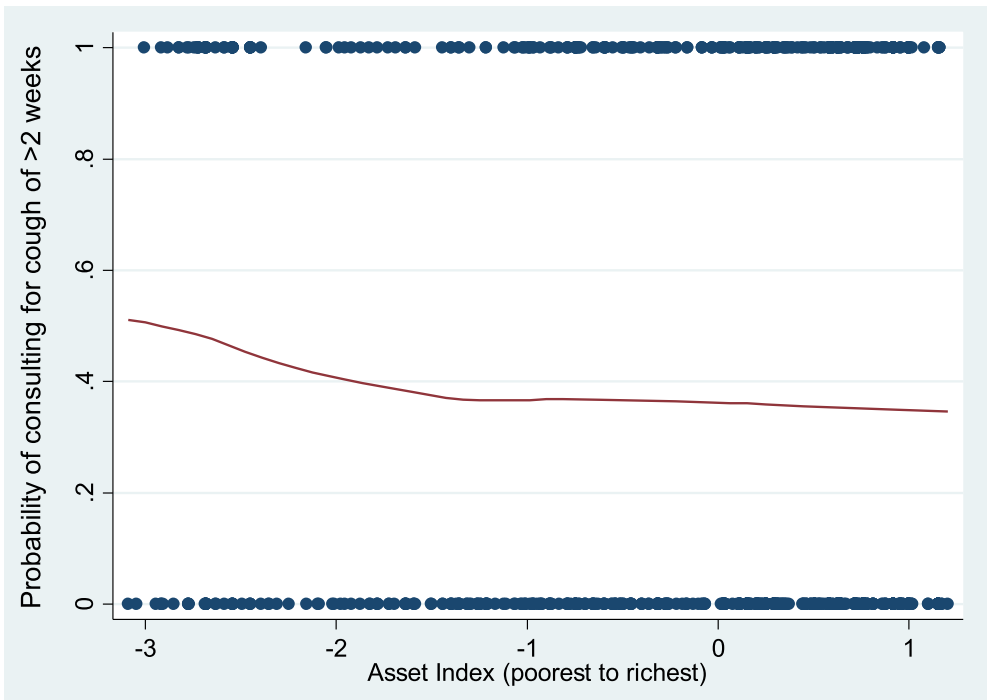

Fig. 1 Probability of consulting by SES, 2010. Scatter plot and curve of best fit showing relationship between the probability of coughing (for more than 2 weeks) and the asset index. Source: Own calculations, ZAMSTAR (2010) 
Table 2 Univariate and multivariate logistic regression analysis for consulting for a cough (when coughing for more than 2 weeks), 2010

\begin{tabular}{lllllll}
\hline Variables & \multicolumn{2}{l}{ Univariate $(n=922)^{\mathrm{a}}$} & & \multicolumn{2}{c}{ Multivariate $(n=921)^{\mathrm{b}}$} \\
\cline { 2 - 3 } \cline { 6 - 7 } & $\mathrm{OR}^{\mathrm{C}}\left(95 \% \mathrm{Cl}^{\mathrm{d}}\right)$ & $P$ value & & $\mathrm{OR}(95 \% \mathrm{Cl})$ & $P$ value \\
\hline Stigma index & $0.88(0.76-1.03)$ & 0.13 & & $1.05(0.89-1.24)$ & 0.58 \\
Age $^{\mathrm{e}}$ & $1.01(1.01-1.02)$ & $<0.01$ & & $1.02(1.01-1.04)$ & $<0.01$ \\
Men & $0.76(0.57-0.99)$ & 0.04 & & $0.88(0.63-1.22)$ & 0.44 \\
Black ethnicity & $2.42(1.60-3.67)$ & $<0.01$ & & $1.99(1.28-3.12)$ & $<0.01$ \\
Education $^{f}$ & $1.00(0.97-1.04)$ & 0.87 & & $1.05(1.00-1.10)$ & 0.05 \\
Employed & $0.85(0.63-1.15)$ & 0.29 & & $0.92(0.67-1.27)$ & 0.63 \\
Asset index & $0.87(0.77-0.98)$ & 0.03 & & $0.81(0.71-0.92)$ & $<0.01$ \\
HIV positive & $1.37(0.98-1.91)$ & 0.06 & & $1.30(0.91-1.85)$ & 0.15 \\
Drinks daily & $1.13(0.66-1.95)$ & 0.65 & & $1.43(0.80-2.54)$ & 0.23 \\
Smoked & $0.53(0.40-0.69)$ & $<0.01$ & & $0.63(0.45-0.88)$ & $<0.01$ \\
\hline
\end{tabular}

${ }^{a} n=921$ for age variable

${ }^{b}$ Due to one missing age variable

c $\mathrm{OR}=$ odds ratio

${ }^{\mathrm{d}} \mathrm{Cl}=$ confidence interval

e per year

per year of education

Reference categories for dichotomous variables: Women, Cape coloured ethnicity, Not employed during last year, HIV negative/did not disclose HIV status, Never/occasional/used to drink, Never smoked. All other independent variables are continuous. Source: Own calculations, ZAMSTAR (2010)

ORs, 95\% CIs and $P$-values for the univariate regression are described first, followed by the results for the multivariate regression.

Stigma has a statistically insignificant relationship with the probability of seeking healthcare for a cough of more than 2 weeks (OR $0.88,95 \%$ CI $0.76-1.03, P$ $=0.13 ;$ OR $1.05,95 \%$ CI $0.89-1.24, P=0.58)$. The stigma result remained insignificant (OR 0.96, 95\% CI $0.82-1.12, P=0.59)$ even when the multivariate regression was rerun without the variables for SES and ethnicity.

The odds ratio of men consulting is less than one in the univariate regression (OR $0.76,95 \%$ CI $0.57-0.99, P$ $=0.04)$ but this becomes statistically insignificant in the multivariate regression (OR $0.88,95 \%$ CI $0.63-1.22, P$ $=0.44$ ). Employment does not show any significant relationship with the likelihood of consulting though the likelihood of the employed consulting is consistently less than the unemployed (OR $0.85,95 \%$ CI $0.63-1.15, P$ $=0.29$; OR 0.92, 95\% CI 0.67-1.27, $P=0.63$ ). Being of black ethnic origin and a year older is associated with a higher likelihood of consulting (OR 2.42, 95\% CI 1.603.67, $P<0.01$; OR 1.99, 95\% CI 1.28-3.12, $P<0.01$ and OR 1.01, 95\% CI 1.01-1.02, $P<0.01$; OR $1.02,95 \%$ CI $1.01-1.04, P<0.01$, respectively). In the case of respondents of black ethnic origin, the reference case is respondents of Cape coloured ethnic origin.

The odds ratio of consulting for each standard deviation increase in the asset index was less than one
(OR $0.87,95 \%$ CI $0.77-0.98, P=0.03$; OR $0.81,95 \%$ CI $0.71-0.92, P<0.01)$. For each additional year of education, the odds of consulting was 1.05 times more likely in the multivariate results (OR 1.00, 95\% CI $0.97-1.04, P=0.87$; OR 1.05, 95\% CI 1.00-1.10, $P=0.05$ ).

$H I V$-positive individuals were more likely to consult than their HIV-negative counterparts or those who did not disclose their HIV status (OR 1.37, 95\% CI 0.98-1.91, $P=0.06$; OR $1.30,95 \%$ CI $0.91-1.85, P=0.15)$ but these findings are not statistically significant in the multivariate regression. There was no significant increased likelihood of consulting for drinking daily (OR 1.13, 95\% CI 0.66$1.95, P=0.65$; OR $1.43,95 \%$ CI $0.80-2.54, P=0.23)$. Persons having smoked were significantly less likely to consult (OR 0.53, 95\% CI 0.40-0.69, $P<0.01$; OR 0.63, 95\% CI $0.45-0.88, P<0.01)$.

\section{Discussion}

Only $37 \%$ of respondents had consulted someone when coughing for more than 2 weeks. Respondents of black ethnic origin (OR 1.99, 95\% CI 1.28-3.12, $P<0.01$ ), those with higher levels of education (OR 1.05 per year of education, 95\% CI 1.00-1.10, $P=0.05$ ), and older respondents (OR 1.02 per year, 95\% CI 1.01-1.04, $P<0.01$ ) had a higher likelihood of consulting for a chronic cough. The opposite held for those who smoked (OR 0.63, 95\% CI 0.45-0.88, $P<0.01)$ and those with higher levels of socio-economic status (OR 0.81, 95\% CI 0.71-0.92, $P<0.01$ ).

\section{Limitations}

The nature of cross-sectional analysis restricts the scope for proving causality. No data were available for one of the more prominent predictors of health-seeking behaviour in the TB literature: TB knowledge levels.

Our data is derived from communities where there is a high prevalence of TB. It is plausible that a gap would exist between stigma scores of TB positive households and non-TB positive households in these communities. However, most important is the relative stigma scores and that it is comparable across communities.

\section{Interpretation}

Compared to similar studies in developing countries, the proportion of respondents who consulted for a chronic cough is relatively low [23, 24]. This is a worrying finding considering that data were collected in high burden communities with $\mathrm{TB}$ notification rates of more than 400/100000.

Using the multivariate analysis approach we find no evidence of a role for stigma in health-seeking behaviour amongst persons coughing for more than 2 weeks, but caution against assuming that this means stigma does not present an important constraint to health-seeking behaviour. Given the strong qualitative evidence of a role 
for stigma in health-seeking [25], one explanation for the lack of quantitative evidence may be that it is not measured well given the challenges of truthfully extracting information on prejudice and bias against $\mathrm{TB}$ sufferers. The insignificance of our stigma variable alongside others may thus be partly attributable to the difficulty in accurately capturing stigma via self-reported measures due to social desirability bias and partly to not triangulating this finding with other data sources, including qualitative data. These findings add impetus to the global call for improved tools for measuring stigma and evaluating stigma interventions [26].

Contrary to some studies on health-seeking behaviour [3, 27-29], gender and employment status do not seem to be significantly associated with the probability of seeking healthcare in the multivariate analysis. However, the models consistently show that men are less likely to consult than women, which is in keeping [8, 24, 30-33] with health-seeking literature.

The employed and those with higher levels of SES are consistently less likely to consult. This negative association is supported by most SES and health-seeking findings [6, 34-36]. It is conceivable that below a certain household income threshold, the opportunity cost of working would be relatively higher when compared to those above the threshold. This may explain the negative relationship between these SES variables and health-seeking behaviour.

Cultural dynamics not fully captured in the stigma variable may explain the relatively large, statistically significant differential in the relationship between ethnicity and health-seeking behaviour. Confirming previous findings in the health-seeking literature [8], we find that the educated were significantly more likely to consult. Older individuals were also more likely to consult. We accounted for the possibility of a non-linear relationship between age and health-seeking behaviour in the multivariate analysis (OR 1.00, $P=0.17$ ) and found that at older ages this relationship persists, which is in contrast with the health-seeking literature $[7,8]$.

The positive association between HIV and consulting is not significant, but this may be due to an under-reporting of HIV positive cases.

Having smoked is the only significant lifestyle choice variable, with those having smoked being less likely to consult. It is possible that those who have smoked attribute their symptoms to smoking rather than TB [37]. This relationship may be driven by the harmful consequences smoking has on the lungs and immune system. It is also plausible that having 'ever smoked' captures unobservable characteristics which may influence one's likelihood of consulting.

\section{Generalisability}

External validity is limited to high TB-prevalence communities in South Africa but given South Africa's high
TB prevalence and incidence, these findings are still of international interest. Finding no role for stigma in health-seeking behaviour is important because it highlights the need to triangulate methods and debate how stigma measures interact with other factors in multivariate analyses.

\section{Conclusion}

Most persons coughing for more than 2 weeks did not seek consultation about their chronic cough. Respondents of black ethnic origin, those with higher levels of education and older respondents had a greater likelihood of consulting. Smokers and those with higher SES were less likely to consult.

TB-control programmes should be more cognisant of the patient characteristics of presumptive TB patients who do not seek care. This information can assist policymakers in designing more targeted TB screening and active case-finding interventions. In the high TB burden communities of South Africa, such interventions may benefit from focusing on youth, those with lower levels of education, smokers, higher SES subgroups and also the population of Cape coloured ethnic origin. These findings add to the meagre body of literature analysing the health-seeking behaviour of this vulnerable and important population.

Our study responds to the global call to address stigma in the fight against TB by being the first (as far as we know) to include a quantitative measure of TB stigma in modelling health-seeking behaviour. Our uniquely comprehensive data set allows us to address this gap in patient-focused analysis of health-seeking decisions. Although we find no role for stigma in health-seeking behaviour, it is important because it highlights the need to triangulate methods and debate how stigma measures interact with other factors.

\section{Additional files}

Additional file 1: SES indicator set. Table showing SES components collected in the ZAMSTAR study that was used to create an asset index for this study. (DOCX $13 \mathrm{~kb}$ )

Additional file 2: Correlation between components of asset index and asset index. Table showing correlation between components of asset index and asset index. (DOCX $14 \mathrm{~kb}$ )

Additional file 3: TB-stigma indicator set. Table showing TB-stigma indicator set used in the SOCS study. (DOCX $13 \mathrm{~kb}$ )

Additional file 4: Stigma level by community (a), age (b) and gender (c). Figures (a-c) showing mean stigma index levels (standardised using $z$-score) for each community $(1-8)$, for each age category $(<18$ years, $18-24$ years, $25-45$ years, $46-60$ years, $61+$ years) and for each gender (women and men). Source: own calculations, SOCS of ZAMSTAR (2008/2009). (DOCX 26 kb)

\section{Abbreviations}

HIV: Human immunodeficiency virus; MCA: Multiple correspondence analysis; RESET: Regression-error specification test; SES: Socio-economic status; 
SOCS: Secondary outcome cohort study; TB: Tuberculosis; WHO: World Health Organization; ZAMSTAR: Zambia and South Africa TB and AIDS Reduction

\section{Acknowledgements}

Academic support from ReSEP (Research on Socio-Economic Policy) is acknowledged. The authors thank the participants and communities who participated in ZAMSTAR SOCS. We would like to thank the ZAMSTAR PIs, Nulda Beyers, Helen Ayles, Peter Godfrey-Faussett, and the CREATE Consortium, under the leadership of Richard Chaisson, for allowing us to use the data.

\section{Funding}

This work is based on the research supported in part by the National Research Foundation of South Africa (Grant Numbers: RCA13102556861 CPRR150722129596 and SDG160531166953). ZAMSTAR was supported by a sub-contract from John Hopkins University, Baltimore, MD, USA, with funds provided by grant number 19790.01 from the Bill and Melinda Gates Foundation, Seattle, WA, USA. The funding bodies played no role in the in the design of the study and collection, analysis, and interpretation of data, nor in writing the manuscript.

\section{Availability of data and materials}

Data are available upon request from the corresponding author.

\section{Authors' contributions}

$\mathrm{RB}$ and $\mathrm{CC}$ conceived and designed the study; $\mathrm{MC}$ and VB participated in data acquisition; CC analysed and interpreted the data; CB provided technical inputs; MC provided clinical inputs; VB provided anthropological inputs; CC wrote the paper; all authors have read, edited and approved the manuscript.

\section{Ethics approval and consent to participate}

We have permission from the ZAMSTAR principal investigators to use the ZAMSTAR and SOCS data in this secondary analysis. Ethics approval for the ZAMSTAR and SOCS studies were obtained from the Biomedical Ethics Committee at the University of Zambia, Lusaka, Zambia; the Stellenbosch Health Research Ethics Committee, Tygerberg, South Africa; and the London School of Hygiene \& Tropical Medicine, London, UK. Individual written consent was obtained from all participants included in the ZAMSTAR SOCS cohort. Ethics approval for this study was obtained from the Research Ethics Committee: Human Research (Humanities) at Stellenbosch University, Stellenbosch, South Africa (project number SU-HSD-004732).

\section{Consent for publication}

Not applicable for this study.

\section{Competing interests}

The authors declare that they have no competing interest.

\section{Publisher's Note}

Springer Nature remains neutral with regard to jurisdictional claims in published maps and institutional affiliations.

\section{Author details}

${ }^{1}$ Department of Economics, Stellenbosch University, Matieland 7602, South Africa. ${ }^{2}$ Department of Economics, University of the Western Cape, Bellville 7535, South Africa. ${ }^{3}$ Desmond Tutu TB Centre, Department of Paediatrics and Child Health, Stellenbosch University, Tygerberg 7505, South Africa. ${ }^{4}$ Department of Global Health and Development, Faculty of Public Health and Policy, London School of Hygiene and Tropical Medicine, 15-17 Tavistock Place, London WC1H9SH, UK. ${ }^{5}$ Zambart, School of Public Health, University of Zambia, PO Box 50697, Lusaka, Zambia.

\section{Received: 9 August 2018 Accepted: 6 March 2019}

\section{Published online: 13 March 2019}

\section{References}

1. Corbett EL, Watt CJ, Walker N, et al. The growing burden of tuberculosis: global trends and interactions with the HIV epidemic. Arch Intern Med. 2003;163:1009-21. https://doi.org/10.1001/archinte.163.9.1009.
2. World Health Organisation. Global Tuberculosis report 2016. Geneva: WHO; 2016.

3. Meintjes G, Schoeman H, Morroni C, Wilson D, Maartens G. Patient and provider delay in tuberculosis suspects from communities with a high HIV prevalence in South Africa: a cross-sectional study. BMC Infect Dis. 2008;8. https://doi.org/10.1186/1471-2334-8-72.

4. Golub JE, Bur S, Cronin WA, Gange S, Baruch N, Comstock GW, et al. Delayed tuberculosis diagnosis and tuberculosis transmission. Int J Tuberc Lung Dis. 2006;10:24-30.

5. Bond V, Chileshe M, Magazi B, Sullivan C. The converging impact of tuberculosis, AIDS, and food insecurity in Zambia and South Africa. Renew Policy Br. 2008:5-6.

6. Asch S, Leake B, Anderson R, Gelberg L. Why do symptomatic patients delay obtaining Care for Tuberculosis? Am J Respir Crit Care Med. 1998;157:12448. https://doi.org/10.1164/ajrccm.157.4.9709071.

7. Godfrey-Faussett P, Kaunda H, Kamanga J, van Beers S, van Cleeff M, Kumwenda-Phiri R, et al. Why do patients with a cough delay seeking care at Lusaka urban health centres? A health systems research approach. Int J Tuberc Lung Dis Off J Int Union Tuberc Lung Dis. 2002;6:796-805.

8. Storla DG, Yimer S, Bjune GA. A systematic review of delay in the diagnosis and treatment of tuberculosis. BMC Public Health. 2008;8:15. https://doi.org/ 10.1186/1471-2458-8-15.

9. Needham DM, Foster SD, Tomlinson G, Godfrey-Faussett P. Socio-economic, gender and health services factors affecting diagnostic delay for tuberculosis patients in urban Zambia. Tropical Med Int Health. 2001;6:2569. https://doi.org/10.1046/j.1365-3156.2001.00709.x.

10. Lawn SD, Afful B, Acheampong JW. Pulmonary tuberculosis: diagnostic delay in Ghanaian adults. Int J Tuberc Lung Dis. 1998;2:635-40.

11. Franco J, Blanquer R, Flores J, Fernández E, Plaza P, Nogueira JM. Analysis of the diagnostic delay in tuberculosis. Med Clin (Barc). 1996;107:453-7.

12. Ngamvithayapong J, Yanai H, Winkvist A, Diwan V. Health seeking behaviour and diagnosis for pulmonary tuberculosis in an HIV-epidemic mountainous area of Thailand. Int J Tuberc Lung Dis Off J Int Union Tuberc Lung Dis. 2001;5:1013-20.

13. Goosby E, Mitchell EMH, Daftary A, Fekadu E, Reid MJA. To end TB, first-ever high-level meeting on tuberculosis must address stigma. Am J Trop Med Hyg. 2018;99:1114-6. https://doi.org/10.4269/ajtmh.18-0591.

14. Marais BJ, Raviglione MC, Donald PR, Harries AD, Kritski AL, Graham SM, et al. Scale-up of services and research priorities for diagnosis, management, and control of tuberculosis: a call to action. Lancet. 2010;375:2179-91. https://doi.org/10.1016/S0140-6736(10)60554-5.

15. World Bank. Incidence of tuberculosis (per 100,000 people) | data. [cited 16 Feb 2019]. Available: https://data.worldbank.org/indicator/SH.TBS.INCD?end= 2011\&locations=ZM-ZA\&start=2010.

16. Ayles H, Muyoyeta M, Du Toit E, Schaap A, Floyd S, Simwinga M, et al. Effect of household and community interventions on the burden of tuberculosis in southern Africa: the ZAMSTAR community-randomised trial. Lancet. 2013; 382:1183-94.

17. Bond V, Floyd S, Fenty J, Schaap A, Godfrey-Faussett P, Claassens M, et al. Secondary analysis of tuberculosis stigma data from a cluster randomised trial in Zambia and South Africa (ZAMSTAR). Int J Tuberc Lung Dis. 2017;21: 49-59. https://doi.org/10.5588/ijtld.16.0920.

18. Corbett EL, Zezai A, Cheung YB, Bandason T, Dauya E, Munyati SS, et al. Provider-initiated symptom screening for tuberculosis in Zimbabwe: diagnostic value and the effect of HIV status. Bull World Health Organ. 2010;88:13-21.

19. Greenacre M, Blasius J. Multiple correspondence analysis and related methods: CRC Press; 2006.

20. Filmer D, Pritchett L. Estimating wealth effects without expenditure data--or tears: an application to educational enrollments in states of India. Demography. 2001;38:115-32. https://doi.org/10.1353/dem.2001.0003.

21. Filmer D, Scott K. Assessing asset indices. Demography. 2012;49:359-92. https://doi.org/10.1007/s13524-011-0077-5.

22. Jones A. Applied econometrics for health economists: a practical guide. Taylorfrancis.com; 2007.

23. Kasse Y, Jasseh M, Corrah T, Donkor SA, Antonnio M, Jallow A, et al. Health seeking behaviour, health system experience and tuberculosis case finding in Gambians with cough. BMC Public Health. 2006;6. https://doi.org/10. 1186/1471-2458-6-143.

24. Hoa NP, Thorson AEK, Long NH, Diwan VK. Knowledge of tuberculosis and associated health-seeking behaviour among rural Vietnamese adults with a 
cough for at least three weeks. Scand J Public Health. 2003;31:59-65. https://doi.org/10.1080/14034950310015121.

25. Courtwright A, Turner AN. Tuberculosis and stigmatization: pathways and interventions. Public Health Rep. 2010;125:34-42. https://doi.org/10.1177/ 003335491012505407.

26. Macintyre K, Bakker MI, Bergson S, Bhavaraju R, Bond V, Chikovore J, et al. Defining the research agenda to measure and reduce tuberculosis stigmas. Int J Tuberc Lung Dis. 2017;21:87-96. https://doi.org/10.5588/ijtld.17.0151.

27. Lim W-Y, Ma S, Heng D, Bhalla V, Chew SK. Gender, ethnicity, health behaviour \& self-rated health in Singapore. BMC Public Health. 2007;7:184. https://doi.org/10.1186/1471-2458-7-184.

28. Phaswana-Mafuya N, Peltzer K, Chirinda W, Kose Z, Hoosain E, Ramlagan S, et al. Self-rated health and associated factors among older south Africans: evidence from the study on global ageing and adult health. Glob Health Action. 2013:6:19880. https://doi.org/10.3402/gha.v6i0.19880.

29. Chikovore J, Hart G, Kumwenda M, Chipungu G, Desmond N, Corbett EL. TB and HIV stigma compounded by threatened masculinity: implications for TB health-care seeking in Malawi. Int J Tuberc Lung Dis. 2017;21:26-33. https:// doi.org/10.5588/ijtld.16.0925.

30. Hooi LN. Case-finding for pulmonary tuberculosis in Penang. Med J Malays. 1994:49.

31. Rajeswari R, Chandrasekaran V, Suhadev M, Sivasubramaniam S, Sudha G, Renu G. Factors associated with patient and health system delays in the diagnosis of tuberculosis in South India. Int J Tuberc Lung Dis. 2002;6.

32. Steen TW, Mazonde GN. Pulmonary tuberculosis in Kweneng District, Botswana: delays in diagnosis in 212 smear-positive patients. Int J Tuberc Lung Dis. 1998;2.

33. Thorson A, Hoa N, Long N. Health-seeking behaviour of individuals with a cough of more than 3 weeks. Lancet. 2000;356:1823-4. https://doi.org/10. 1016/S0140-6736(00)03241-4.

34. Yimer S, Bjune G, Alene G. Diagnostic and treatment delay among pulmonary tuberculosis patients in Ethiopia: a cross sectional study. BMC Infect Dis. 2005;5. https://doi.org/10.1186/1471-2334-5-112.

35. Niijima Y, Yamagishi F, Suzuki K, Yasuda J, Shirai T, Satoh N, et al. Patient's delay and doctor's delay in the primary treatment cases of pulmonary tuberculosis detected by subjective symptoms. Kekkaku. 1990:65.

36. Salaniponi FM, Harries AD, Banda HT, Kang'ombe C, Mphasa N, Mwale $A$, et al. Care seeking behaviour and diagnostic processes in patients with smear-positive pulmonary tuberculosis in Malawi. Int J Tuberc Lung Dis. 2000;4:327-32.

37. Lönnroth K, Holtz TH, Cobelens F, Chua J, van Leth F, Tupasi T, et al. Inclusion of information on risk factors, socio-economic status and health seeking in a tuberculosis prevalence survey [educational series. Serialised guidelines. Assessing tuberculosis prevalence through population-based surveys. Number 6 in the series]. Feb 2009 [cited 4 Jul 2018]. Available: https://www.researchgate.net/profile/Timothy_Holtz/publication/ 233496569_Inclusion_of_information_on_risk_factors_socio-economic _ status_and_health_seeking_in_a_tuberculosis_prevalence_survey_ Educational_series_Serialised_guidelines_Assessing_tuberculosis_ prevalence_through/links/00b7d5164e13cd50dc000000.pdf.

Ready to submit your research? Choose BMC and benefit from:

- fast, convenient online submission

- thorough peer review by experienced researchers in your field

- rapid publication on acceptance

- support for research data, including large and complex data types

- gold Open Access which fosters wider collaboration and increased citations

- maximum visibility for your research: over $100 \mathrm{M}$ website views per year

At BMC, research is always in progress.

Learn more biomedcentral.com/submissions 